https://www.journal-imab-bg.org

Original article

\title{
NEW APPROACHES IN THE TREATMENT OF TYPE 2 DIABETES - TRANSITION FROM GLUCOSE-CENTRED TO PATIENT-CENTRED MODEL
}

\author{
Antoaneta Tsvetkova, Silvia Mihaylova. \\ Medical College, Medical University - Varna, Bulgaria.
}

\begin{abstract}
Objective: The high prevalence of Type 2 diabetes mellitus (T2D) all over the world cause a high demand of searching for new antidiabetic drugs. The present study aims to identify the consumption of three new classes of antidiabetic drugs (DPP-4 inhibitors, GLP-1 receptor agonists, and SGLT-2 inhibitors), analyzing the use of these drugs prescribed for the treatment of T2D. In this retrospective observational study, we analyzed consumption data for the period 2015-2020, obtained from National Health Insurance Fund (NHIF) database only.

Results: The NHIF expenditure of DPP-4 inhibitors, GLP-1 receptor agonists, and SGLT-2 inhibitors in Bulgaria for the period 2015-2020 is increasing. Although last introduced into clinical practice, SGLT-2 inhibitors were preferred by clinicians, over GLP-1 agonists, during the considered period.

Conclusions: DPP-4 inhibitors, GLP-1 receptor agonists, and SGLT-2 inhibitors consumption in Bulgaria indicates progressive changes in the prescription of antidiabetic drugs. We have highlighted the market uptake of drugs approved during the last 15 years. To ensure the optimal benefits to the patient, we feel it is necessary to implement guidance to assist prescribers in choosing the most appropriate therapy based on drug and patient characteristics. Further monitoring of the effect of the pharmacotherapeutic changes on additional cardiovascular and renal benefits of these drugs is needed.
\end{abstract}

Keywords: type 2 diabetes, NHIF, PRAC, DPP- 4 inhibitors, GLP-1 receptor agonist, SGLT-2 inhibitors,

\section{INTRODUCTION:}

Diabetes mellitus (DM) is a chronic metabolic disorder characterized by hyperglycaemia due to insulin resistance, insufficient insulin secretion, or both. Eight pathogenic abnormalities, referred to as the "ominous octet" by Ralph Defronzo, lead to the evolution of type 2 diabetes mellitus (T2D) (impaired insulin secretion from pancreatic $\beta$-cells; increased glucagon secretion from pancreatic ácells; increase in hepatic glucose production; decreased muscle glucose uptake; increased lipolysis; reduced incretin effect - impaired intestinal secretion of glucagonlike peptide-1 (GLP-1); increased renal glucose reabsorp- tion; neurotransmitter dysfunction [1].

The treatment goal is to maintain glycaemic control, with glycated haemoglobin levels (HbAlc) between 6.5$7.0 \%(48-53 \mathrm{mmol} / \mathrm{mol})$. Antidiabetic drugs have a diverse mechanism of action. In the last 15 years, three new groups of products were introduced into clinical practice. These are GLP-1 receptor agonists, DPP IV (dipeptidyl peptidase IV) inhibitors, and SGLT-2 (sodium-glucose cotransporter2) inhibitors (fig.1).

\section{GLP-1 receptor agonists (GLP-1 RA)}

Glucagon-like peptide-1 (GLP-1) and glucose-dependent insulinotropic polypeptide (GIP) are two main hormones (incretins) promoting glucose removal by stimulating the release of insulin from the pancreas. Secretion of GLP-1 occurs from the enteroendocrine L cells of the distal small intestine, whereas GIP is mainly secreted from the $\mathrm{K}$ cells in the proximal small intestine. GLP-1 may also play a role in the proliferation of beta cells and the decrease in beta-cell apoptosis. Circulating levels of GLP-1 are low in the fasting state and rise quickly after meals [2]. GLP-1 is rapidly inactivated (half-life less than 2 minutes) by dipeptidyl peptidase-4 (DPP-4), an enzyme that cleaves the peptide bond between alanine (Ala8) and glutamic acid (Glu9) [3]. GLP-1 RA are peptide medicines resistant to DPP-4 degradation. Initial structure-activity relationship studies of endogenous GLP-1, conducted by Adelhorst et al. [4], discover key domains of the sequence that are determinants for pharmacological activity and enzyme stability. After alanine scanning, it has been proved that $\mathrm{N}$ terminal amino residues histidine (His7), glycine (Gly10), phenylalanine (Phe12), threonine (Thr13), and aspartic acid (Asp15) are essential for the interaction with the GLP-1 receptor. Substitution of these amino acid residues with LAla leads to a loss of binding affinity. C-terminal amino acids phenylalanine (Phe28) and isoleucine (Ile29) are also important for receptor binding since they participate in maintaining the secondary peptide structure [4]. GLP-1 RA potentiate glucose-stimulated postprandial insulin secretion from $\beta$-cells and suppress glucagon release from pancreatic $\alpha$-cells. Based on pharmacokinetic properties and the duration of hypoglycaemic action, they are classified into two groups - short-acting (daily administration) and longacting (weekly administration). 
Fig. 1. History of pharmacological treatment of T2D

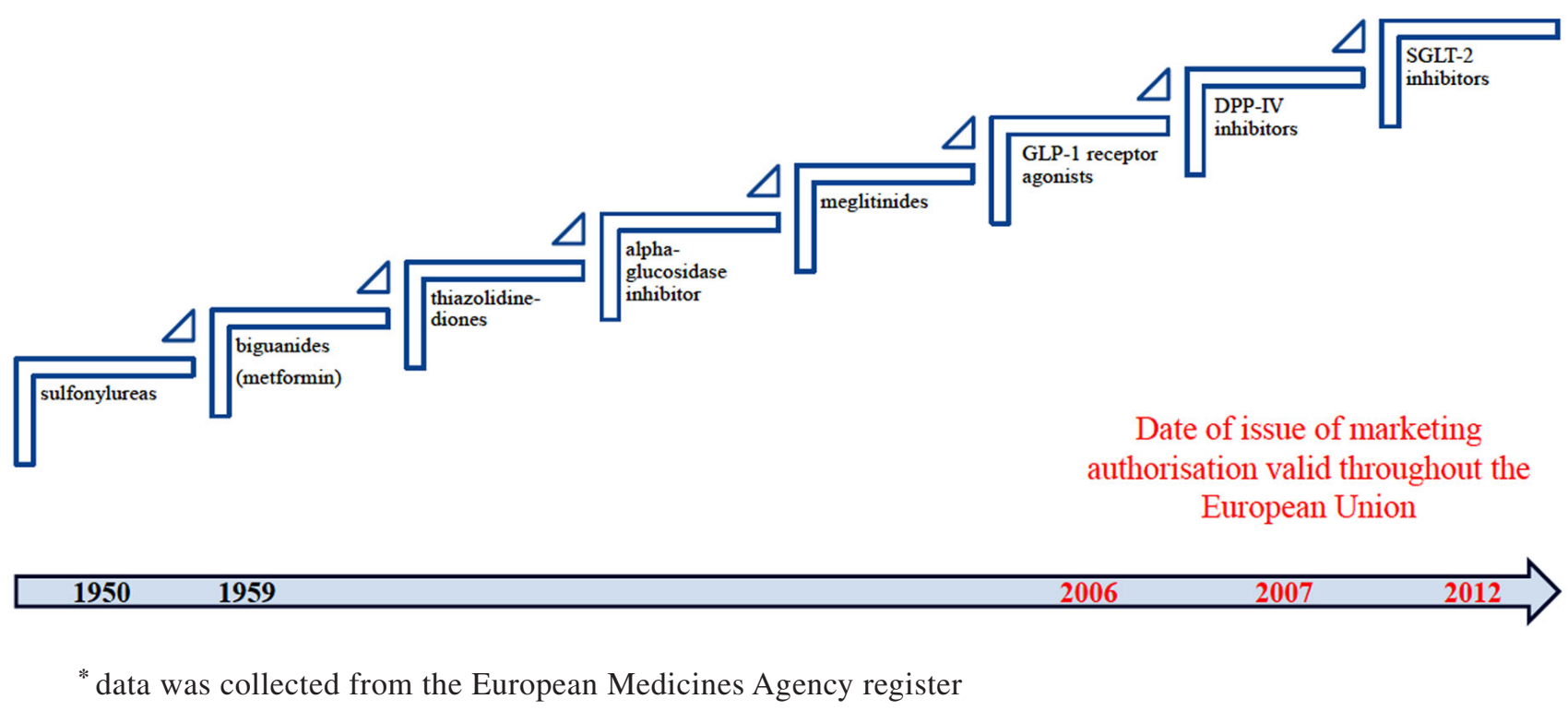

- Short-acting (exenatide, liraglutide, lixisenatide)

Exenatide is a 39-amino acid peptide GLP-1 receptor agonist with $50 \%$ homology to human GLP-1 and it is resistant to the action of DPP-4 ( $\mathrm{t}_{1 / 2}=2.4$ hours $)$. It is the synthetic version of exendin-4. This was among several bioactive peptides containing an N-terminal histidine identified in crude venom preparations extracted from the perimandibular salivary glands of Helodermatidae lizards [5]. Exenatide was the first GLP-1 receptor agonist on the market, receiving approval by the European Medicines Agency (EMA) in 2006. In the structure of liraglutide, N-hexadecane acid (C16) is covalently bonded at position 26 - lysine (Lys) through gamma glutamate (ãGlu) as a linker and Lys34 is substituted by arginine (Arg). The presence of fatty acids leads to an easy and reversible binding to serum albumin through hydrophobic and ionic interactions. Albumin binding provides a steric hindrance against enzymatic degradation of the acylated peptide and slows its renal clearance due to the large size of the peptide-albumin complex. It also increases liraglutide plasma half-life to 13 hours. Lixisenatide is a synthetic peptide containing 44 amino acids based on exendin- 4 with $50 \%$ homology to human GLP-1. It is derived from the first 39 amino acids in the sequence of the peptide exendin- 4 with an addition of six Lys residues and removal of proline (Pro38) at the Cterminus. The half-life of lixisenatide is $2-4$ hours after s.c. injection [6]. Liraglutide and lixisenatide were granted marketing approval by EMA in 2009 and 2013, respectively.

- Long-acting (albiglutide, dulaglutide, semaglutide) Albiglutide consists of two copies of GLP-1 analogues conjugated to reconvalescent human serum albumin. In both copies of GLP-1, the analogue Ala8 is substituted with Gly for increasing enzyme resistance $\left(\mathrm{t}_{1 / 2}=5\right.$ days $)$. Albiglutide was authorized by EMA in 2014 and withdrawn from the market in 2018 for commercial reasons. It was never registered in Bulgaria. Dulaglutide is a dithiocyclopeptidelinked fusion protein. Each monomer is built of one part GLP-1 analogue, which is covalently bondedthrough a small peptide linker to one $\mathrm{Fc}$ region of human $\mathrm{IgG} 4$. In the structure of the GLP-1 analogue, Ala8 is substituted for Gly to avoid enzymatic degradation by DPP-4, and Gly36 is substituted with Arg to avoid potential interaction with T-cells. In comparison to liraglutide, there is an additional amino acid substitution at position 8 in the structure of semaglutide. Ala8 is substituted with the non-proteinogenic amino acid 2-aminoisobutyric acid (Aib) to prevent the degradation of DPP-4. At position 26 (Lys), using a yGlu-2x OEG linker, a steric (C18) long-chain fatty acid was added [7]. These modifications lead to an extension of the plasma "half-life" of semaglutide to 165 hours. Dulaglutide and semaglutide were granted marketing approval by EMA in 2014 and 2018, respectively.

DPP-4 inhibitors (sitagliptin, vildagliptin, linagliptin, saxagliptin)

DPP-4 inhibitors are small synthetic molecules that are administered orally. Sitagliptin is triazolopyrazine, beta-amino acid-derived. Vildagliptin and saxagliptin are cyanopyrrolidine-based inhibitors of DPP-4. Linagliptin is a member of quinazolines and aminopiperidine. It derives from 7H-xanthine [8]. Between 2007 and 2011, EMA approved several DPP-4 inhibitors, such as sitagliptin (2007), vildagliptin (2007), saxagliptin (2009), and linagliptin (2011). Gliptins slow the inactivation and degradation of GLP-1 by inhibiting the activity of the DPP-4 enzyme and offering treatment possibilities for T2D.

SGLT-2 inhibitors (dapagliflozin, canagliflozin, empagliflozin)

This is the latest class of medicinal products approved for the treatment of T2D. Sodium-glucose co-trans- 
porter (SGLT) is a protein that expressed in the proximal tubules and mediates the reabsorption of $90 \%$ of filtrated glucose. Inhibiting the action of SGLT reduces glucose reabsorption resulting in increased excretion of glucose into urine and lowering its concentration in blood plasma. SGLT-2 inhibitors are small synthetic molecules that are administered orally. They are representative compounds of aromatic C-glycosides [9]. The first product of this class, dapagliflozin, receiving approval by EMA in 2012. In 2013 and 2014, EMA approved two new SGLT-2 inhibitors - canagliflozin (2013) and empagliflozin (2014).

\section{OBJECTIVE:}

The objective of this study was to identify and characterize the drug utilization of the three new groups of antidiabetic drugs (DPP-4 inhibitors, GLP-1 RA, and SGLT-2 inhibitors) in Bulgaria, for the period 2015-2020, with special attention to new diabetic treatment algorithms in Bulgaria.

\section{MATERIALS AND METHODS:}

A retrospective observational study has been performed. Usage data (in BGN) for the period 2015-2020 was obtained from NHIF database only. Consumption charged to mutual or other insurance companies was not included in the present study, nor was private prescription consumption. Drug identification was performed considering the ATC (Anatomical Therapeutic Chemical) classification system.

\section{RESULTS AND DISCUSSION}

In Bulgaria, there is an increasing tendency in cases with diabetes mellites. While some 30 years ago diabetic patients were $3 \%$ of the population, now they are over $8 \%$ that is even higher than the European average $-7 \%$. The treatment of T2D is characterized by the initiation, switching and addition of antidiabetic medications in order to achieve and maintain sustained blood glucose levels. The three new classes of antidiabetic drugs, DPP-4 inhibitors, GLP-1 RA, and SGLT-2 inhibitors, effectively lower blood glucose levels while minimizing the risk of hypoglycaemia [10].

For outpatient treatment of T2D, the NHIF requires a protocol issued by an endocrinologist or by a specialized commission in healthcare facilities that has concluded a contract with the NHIF. In order for a drug to be included in the Positive Reimbursement List (PRL), first, it must be submitted, to the National council of prices and reimbursement of medicinal products (NCPRMP), by Marketing Authorization Holder (MAH). All the three novel classes of antidiabetics entered the Bulgarian pharmaceutical market before 2015; among them, 15 trade names were added in the PRL before 2015, and the remaining 17 were included therefore after. DPP-4 inhibitors, GLP-1 RA, and SGLT-2 inhibitors are reimbursed according to International Classification of Diseases (ICD) codes E11.2, E11.3, E11.4, E11.5 and E11.9. In 2016 and 2017, NHIF paid for those ICD codes 104,616,567 and 102,835,383 BGN, respectively. The three observed antidiabetic drug groups represent around $30.6 \%$ and $31.1 \%$ of that expenditure, respectively. There is a trend this per cent to increase as the sum of expenditure of the whole three groups increased by 20 million leva from 2018 to $2020(111,838,706 \mathrm{BGN}$ and $131,638,694$ BGN, respectively) (fig. 2). The most preferred ICD codes are E11.4 (DM with neurological complications) and E11.9 (DM without complications).

Fig. 2. All drugs reimbursed by NHIF by year by ICD-10 codes (E11.2 to E11.9)

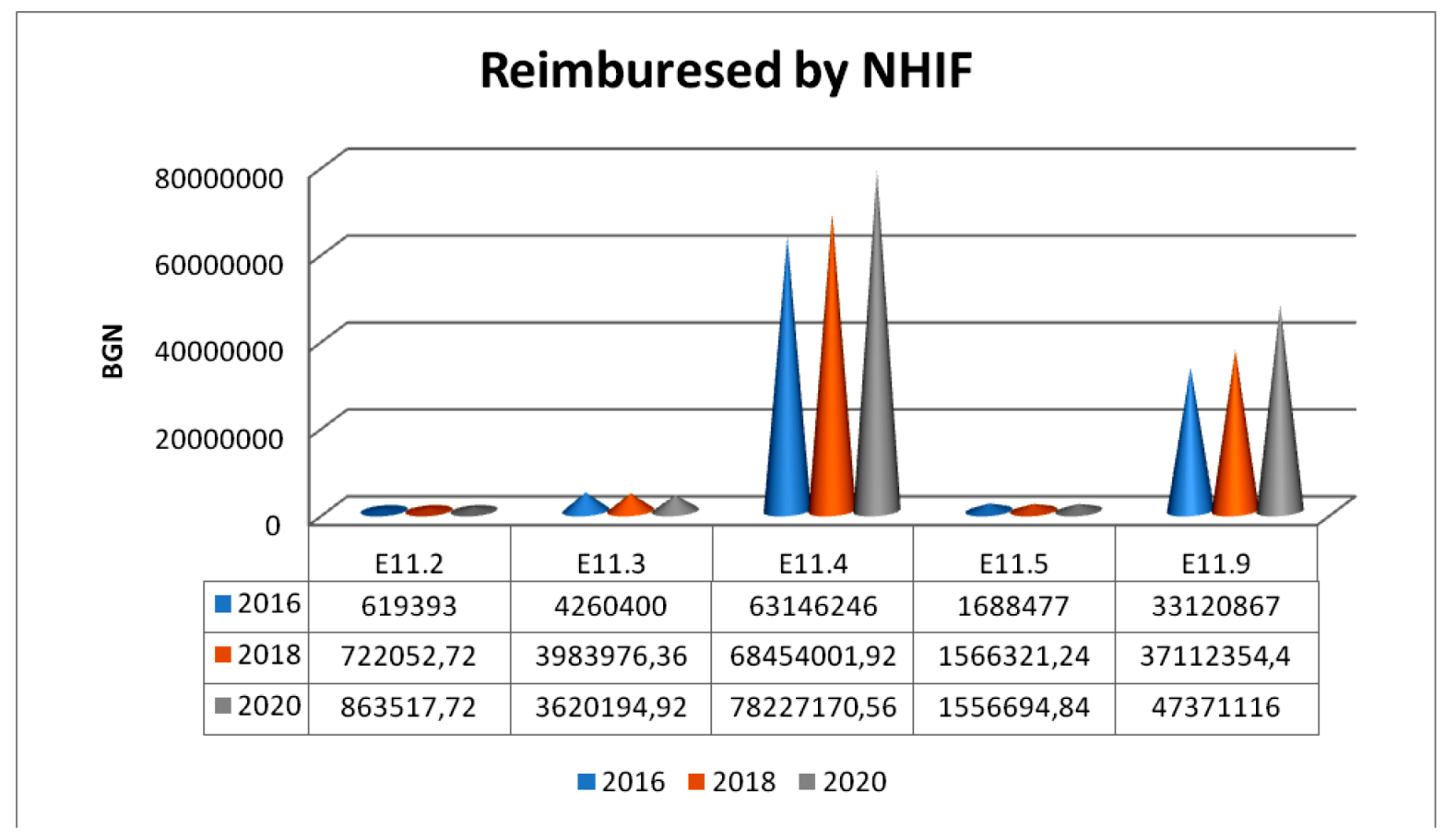

* data was obtained from National Health Insurance Fund database 
The quantities of reimbursed medicines by the NHIF from the classes of GLP-1 RA, DPP-4 inhibitors, and SGLT2 inhibitors, used for the treatment of T2D are presented in Table 1. During the observed period, the most frequently prescribed combinations were vildagliptin + metformin, sitagliptin + metformin, linagliptin+metformin; however, only linagliptin+metformin have a trend towards increasing in use. During the period of 5 years, the usage of liraglutide (GLP-1 RA) has almost doubled, compared to the other members of the group. Another GLP-1 RA, exenatide, has sharply lost its market share since 2015 . Medicinal products containing semaglutide were only included in the PRL in September 2019. In the light that GLP-1 RA are applied parenterally, in September 2019, the U.S. Food and Drug Administration (FDA) issued a marketing authorization for the first and only medicinal product for oral use - semaglutide (Rybelsus). The EMA approved it in April 2020, and it is expected to be reimbursed by the NHIF in the future.

Table 1. Reimbursed medicines by the NHIF from the classes of GLP-1 agonists, DPP-4 inhibitors, and SGLT-2 inhibitors

\begin{tabular}{|c|c|c|c|c|c|c|c|}
\hline & \multirow{2}{*}{ INN } & \multirow{2}{*}{ DDD } & \multicolumn{5}{|c|}{ Expenditure in BGN } \\
\hline & & & 2015 & 2016 & 2017 & 2018 & 2019 \\
\hline \multirow{9}{*}{ 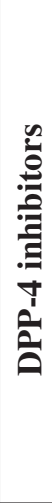 } & Sitagliptin/metformin & 2 tabl & $5,104,216.65$ & $4,591,583.55$ & $4,410,884.35$ & $3,959,766.65$ & $3,276,802.05$ \\
\hline & Vildagliptin/metformin & 2 tabl & $7,863,745.44$ & $7,107,825.96$ & $5,129,863.65$ & $3,547,899.62$ & $3,258,930.49$ \\
\hline & Saxagliptin/metformin & 2 tabl & $1,667,530.32$ & $1,651,406.66$ & $1,450,865.63$ & $1,238,954.08$ & $969,955.15$ \\
\hline & Linagliptin/metformin & 2 tabl & $5,260,720.25$ & $5,969,937.50$ & $6,732,481.17$ & $7,091,470.44$ & $7,252,302.60$ \\
\hline & Sitagliptin & $0.1 \mathrm{~g}$ & $494,757.56$ & $459,079.91$ & $454,537.67$ & $436,981.75$ & $367,835.52$ \\
\hline & Vildagliptin & $0.1 \mathrm{~g}$ & $217,601.56$ & $219,057.01$ & $185,106.31$ & $82,363.55$ & $102,987.38$ \\
\hline & \multirow{2}{*}{ Saxagliptin } & \multirow{2}{*}{$5 \mathrm{mg}$} & \multirow{2}{*}{$184,730.61$} & \multirow{2}{*}{$164,255.16$} & $47,959.10$ & \multirow{2}{*}{ - } & \multirow{2}{*}{ - } \\
\hline & & & & & $* X 06 / 2017$ & & \\
\hline & Linagliptin & $5 \mathrm{mg}$ & $669,102.70$ & $915,197.40$ & $841,601.23$ & $1,169,733.34$ & $1,460,762.19$ \\
\hline \multirow{6}{*}{ 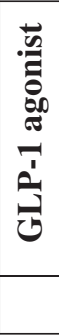 } & Exenatide & $15 \mathrm{mcg}$ & $3,213,879.11$ & $1,743,890.27$ & $349,772.95$ & $273,765.84$ & $204,476.69$ \\
\hline & Liraglutide & $1.5 \mathrm{mg}$ & $5,278,129.38$ & $6,421,027.90$ & $7,139,666.75$ & $7,894,233.27$ & $9,402,342.19$ \\
\hline & \multirow{2}{*}{ Lixisenatide } & \multirow{2}{*}{$20 \mathrm{mcg}$} & $160,129.07$ & \multirow{2}{*}{$615,790.26$} & \multirow{2}{*}{$456,099.24$} & \multirow{2}{*}{$353,135.95$} & \multirow{2}{*}{$242,063.06$} \\
\hline & & & $* \mathrm{R} 02 / 2015$ & & & & \\
\hline & Dulaglutide & $0.16 \mathrm{mg}$ & & & & $* \mathrm{R} 12 / 2018$ & $599,054.68$ \\
\hline & Semaglutide & $0.11 \mathrm{mg}$ & & & & & *R 09/2019 \\
\hline \multirow{7}{*}{ 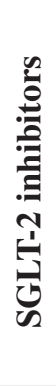 } & \multirow{2}{*}{ Dapagliflozin } & \multirow{2}{*}{$10 \mathrm{mg}$} & $259,148.61$ & \multirow{2}{*}{$634,407.45$} & \multirow{2}{*}{$940,405.02$} & \multirow{2}{*}{$1,163,451.65$} & \multirow{2}{*}{$1,296,346.07$} \\
\hline & & & *R $02 / 2015$ & & & & \\
\hline & \multirow{2}{*}{ Dapagliflozin/metformin } & \multirow{2}{*}{2 tabl } & $30,726.03$ & \multirow{2}{*}{$933,578.10$} & \multirow{2}{*}{$2,393,973.37$} & \multirow{2}{*}{$3,642,886.44$} & \multirow{2}{*}{$4,680,297.63$} \\
\hline & & & $* \mathrm{R} \quad 10 / 2015$ & & & & \\
\hline & Empagliflozin & $17.5 \mathrm{mg}$ & *R $07 / 2015$ & $543,164.57$ & $1,418,426.13$ & $1,868,314.02$ & $2,457,881.22$ \\
\hline & Empagliflozin/metformin & 2 tabl & & $* \mathrm{R} 12 / 2016$ & - & $2,798,134.35$ & $4,777,563.16$ \\
\hline & Canagliflozin & $200 \mathrm{mg}$ & $* \mathrm{R} \quad 10 / 2015$ & - & - & - & $384,004.18$ \\
\hline
\end{tabular}

SGLT-2 inhibitors are the last group introduced to the Bulgarian pharmaceutical market. Canagliflozin was added to the PRL in October 2015, but due to an EMA review of the whole class of SGLT-2 inhibitors, about a potential increased risk of lower limb amputation (mostly affecting the toes), canagliflozin appeared on the Bulgarian pharmaceutical market two years later in 2018. The review of canagliflozin was started at the request of the European Commission on April 15, 2016, under Art. 20 of Regulation 726/2004. On July 7, 2016, the review was expanded to include other drugs in the same class: dapagliflozin and empagliflozin. As a result, the EMA/ PRAC (Pharmacovigilance Risk Assessment Committee) required the MAH to revise the advisory leaflet in the section covering adverse drug reactions [11]. Canagliflozin eventually entered the Bulgarian pharmaceutical market in 2019. Canagliflozin + metformin has also been approved by NCPRMP. As of January 2021, the PRL also includes other drugs from the observed three antidiabetic groups, such as: 
- Empagliflozin/linagliptin - entered RPL in April 2020

- Saxagliptin/Dapagliflozin - entered RPL in December 2020

Although last introduced into clinical practice, SGLT-2 inhibitors are preferred by clinicians over GLP-1 agonists in the considered period. Next in terms of sales are DPP-4 inhibitors, with the smallest market share being that of GLP-1 agonists. SGLT-2 inhibitors are taken orally, which might be a reason for the frequent prescrip- tion (fig. 3). In the period 2015-2019, SGLT-2 inhibitors recorded the highest sales growth because, in addition to lowering HbA1c levels, there were additional benefits, such as reducing body weight, lowering blood pressure and reducing blood urate levels. Weight reduction results from calorie loss due to glucosuria and, additionally, the diuretic effect at the beginning of therapy. According to various studies, patients typically lose between 1 to $5 \mathrm{~kg}$, most of which is visceral fat. Weight loss generally continuous during the course of the treatment at a lower rate than at the beginning of treatment.

Fig. 3. The total number of the three antidiabetic drug classes reimbursed by NHIF between 2015 and 2019 in Bulgaria.

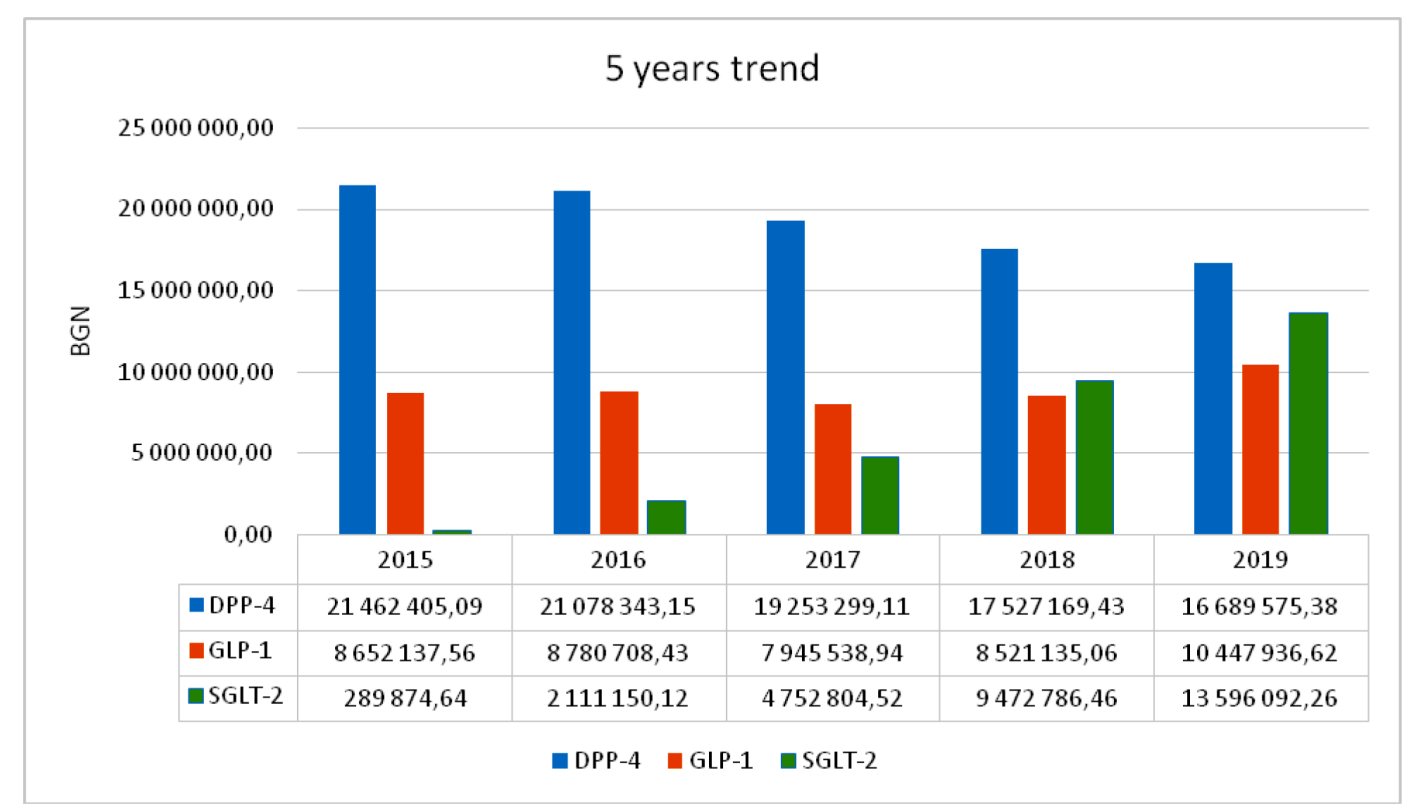

Hypoglycaemic action of SGLT-2 inhibitors is not dependent on insulin levels, which differentiates them from other antidiabetic drugs and allows for combination with any other class of drugs at any stage of T2D, provided there is preserved renal function [12].
The risk of hypoglycaemiais low, with DPP-4 inhibitors and GLP-1 agonists, as their action depends on glucose levels. The glycaemic and non-glycaemic effects of these medicines a represented in Table 2.

Table 2. The glycaemic and non-glycaemic effects of DPP-4 inhibitors, GLP-1 receptor agonists, and SGLT-2 inhibitors

\begin{tabular}{|c|c|c|c|}
\hline & DPP-4 inhibitors & GLP-1 agonists & SGLT-2 inhibitors \\
\hline \multicolumn{4}{|c|}{ Glycaemic effects } \\
\hline \multirow{2}{*}{ 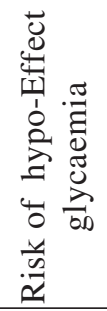 } & $\begin{array}{l}\text { Restore the levels of endogenous } \\
\text { incretins (GLP1 and GIP) }\end{array}$ & $\begin{array}{l}\text { Activate GLP-1 receptors; } \\
\text { Lower postprandial glucose excur- } \\
\text { sions }\end{array}$ & $\begin{array}{l}\text { Effective in all stages of T2D; } \\
\text { Reduce increased glucose reab- } \\
\text { sorption in the proximal tubules }\end{array}$ \\
\hline & $\begin{array}{l}\text { Low } \\
\text { (glucose-dependent effect) }\end{array}$ & $\begin{array}{l}\text { Low } \\
\text { (glucose-dependent effect) }\end{array}$ & $\begin{array}{l}\text { Low } \\
\text { (when not used in combination } \\
\text { with insulin and/or SUs) }\end{array}$ \\
\hline
\end{tabular}




\begin{tabular}{|c|c|c|c|}
\hline \multicolumn{4}{|c|}{ Non-glycaemic effects } \\
\hline Weight & No effect on weight & Weight reduction & Weight reduction \\
\hline 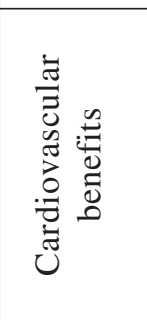 & $\begin{array}{l}\text { Increased risk of hospital admis- } \\
\text { sion for heart failure (saxagliptin, } \\
\text { alogliptin); dosage needs to be } \\
\text { adjusted according to the renal } \\
\text { function, defined by glomerular } \\
\text { filtration (no need for linagliptin); }\end{array}$ & $\begin{array}{l}\text { liraglutide > semaglutide }> \\
\text { exenatide LAR; dulaglutide - } \\
\text { lower rates of cardiovascular } \\
\text { events and mortality; }\end{array}$ & $\begin{array}{l}\text { empagliflozin > canagliflozinA } \\
\text { slight reduction in blood pressure } \\
\text { and a limited effect on serum lipid } \\
\text { profiles (increased HDL choles- } \\
\text { terol and decreased triglycerides) }\end{array}$ \\
\hline 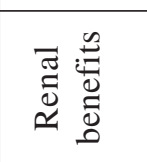 & $\begin{array}{l}\text { Lowering the risk of development } \\
\text { or advancement of both micro-and } \\
\text { macroalbuminuria }\end{array}$ & $\begin{array}{l}\text { Significantly reduced risk of ne- } \\
\text { phropathy: liraglutide > } \\
\text { semaglutide > dulaglutide }\end{array}$ & $\begin{array}{l}\text { Significantly reduced relative risk } \\
\text { of development or worsening of } \\
\text { existing nephropathy; }\end{array}$ \\
\hline $\begin{array}{l}\text { Other side } \\
\text { effects }\end{array}$ & $\begin{array}{l}\text { Gastrointestinal, flu-like symp- } \\
\text { toms, skin reactions }\end{array}$ & $\begin{array}{l}\text { CNS, gastrointestinal, cardiovas- } \\
\text { cular effects }\end{array}$ & Infections, diabetic ketoacidosis \\
\hline
\end{tabular}

International guidelines recommend prescribing metformin as an initial monotherapy as well as in a combination regimen. Fixed-dose combinations (FDC) offer advantages - reduced pill burden and easier administration, greater adherence to therapy and improved medication compliance, giving better therapeutic results. This explains their frequent prescribing. FDC with predominantly metformin $1000 \mathrm{mg}$ being widely used over those with metformin $850 \mathrm{mg}$. The likely reason for this being the reducing effect of metformin on body weight, which is more pronounced at higher doses. GLP-1 agonists and SGLT-2 inhibitors can lead to weight reduction, while DPP-4 inhibitors do not have an effect on body weight. Data in our study revealed that DPP-4/metformin FDCs were more frequently prescribed compared to SGLT-2 inhibitors/ metformin FDCs.

The concept of "precision medicine" of the $P 4$ Medicine approach (Predictive, Preventive, Personalized \& Participatory) outlines new guidelines for the choice of
T2D treatment. The management of T2D is a complex one, where the choice of treatment is patient-centred and focused on the patient's needs and comorbidities [13]. The treatment objectives are the optimization of glycaemic control along with body weight reduction, as well as management of microvascular or macrovascular complications, and lifestyle changes leading to an improvement in "quality of life". The choice of pharmacotherapy needs to consider the presence of risk factors: risk of hypoglycaemia, cardiovascular disease (CVD), heart failure (HF), chronic kidney disease (CKD), contraindications and price. Since 2008, there is a regulatory requirement that all new antidiabetic medicines for the treatment of T2D must be safe for the cardiovascular system [14]. In recent years, resultsfrom several cardiovascular outcome trials have been published for SGLT-2 inhibitors and GLP-1 agonists versus a placebo group (Table 3). The primary composite endpoint was 3point major adverse cardiac events (3P-MACE) - death from cardiovascular causes, nonfatal myocardial infarction, or nonfatal stroke.

Table 3. Completed 3P-MACE clinical trials of SGLT-2 inhibitors and GLP-1 agonist

\begin{tabular}{lllll}
\hline Drug class & Clinical trial & INN & Year & Ref. \\
\hline GLP-1 agonists & LEADER & liraglutide & 2016 & {$[15]$} \\
& SUSTAIN-6 & semaglutide & 2016 & {$[16]$} \\
& HARMONY & albiglutide & 2018 & {$[17]$} \\
& REWIND & dulaglutide & 2019 & {$[18]$} \\
\hline \multirow{2}{*}{ SGLT-2 inhibitors } & EMPA-REG OUTCOME & empagliflozin & 2015 & {$[19]$} \\
& CANVAS Program & canagliflozin & 2017 & {$[20]$} \\
& DECLARE-TIMI 58 & dapagliflozin & 2018 & {$[21]$} \\
\hline
\end{tabular}

\section{Recommendations for Good Clinical Practice in Diabetes Mellitus in Bulgaria}

The latest Recommendations for Good Clinical Practice in Diabetes Mellitus were developed by the Bulgarian Society of Endocrinology in 2019 [22]. First-line therapy is metformin together with a comprehensive change in lifestyle (including weight management and physical activity). If monotherapy does not reach and maintain the target levels of HbA1c over a 3-month period, a second oral or injectable agent must be added. For patients diagnosed with atherosclerotic cardiovascular disease (ASCVD), it is recommended to include a GLP-1 receptor agonist with proven cardiovascular benefits (liraglutide, semaglutide, dulaglutide) and/or an SGLT2 inhibitor (empagliflozin > canagliflozin) with proven cardiovascular benefits and adequate glomerular filtration rate. In patients with HF or 
CKD, an SGLT-2 inhibitor is preferred with evidence for a reduced risk of $\mathrm{HF}$ and/or progression of CKD and adequate glomerular filtration rate. In cases of intolerance or contraindications for SGLT-2 inhibitor or reduced glomerular filtration rate $\left(<45 \mathrm{ml} / \mathrm{min} / 1.73 \mathrm{~m}^{2}\right)$, a GLP-1 receptor agonist with proven cardiovascular benefits is preferred as liraglutide. For patients who need a reduced hypoglycaemia risk, DPP-4 inhibitors, GLP-1 receptor agonists, SGLT2 inhibitors, or thiazolidinediones are preferred.

\section{CONCLUSION}

DPP-4 inhibitors, GLP-1 receptor agonists, and SGLT-2 inhibitors consumption in Bulgaria indicates progressive changes in the prescription of antidiabetic drugs. The new classes of antidiabetic drugs that emerged some
15 years ago have proven to have some benefits in the patient-centred treatment algorithm. In 2018 and 2019, the American Diabetes Association (ADA) and the European Association for the Study of Diabetes (EASD) published a new consensus report and an update for the management of hyperglycaemia in T2D [13, 23]. In these reports, it is highlighted that SGLT-2 inhibitors or GLP-1 agonists, as well as their combination, can have cardiovascular and renal benefits beyond glycaemic control and weight management. The Bulgarian Society of Endocrinology has developed Recommendations for Good Clinical Practice in Diabetes Mellitus, which comply with the recommendations of the ADA and EASD. Further monitoring of the effect of the pharmacotherapeutic changes on additional cardiovascular and renal benefits of these drugs is needed.

\section{REFERENCES:}

1. Defronzo RA. Banting Lecture. From the triumvirate to the ominous octet: a new paradigm for the treatment of type 2 diabetes mellitus. Diabetes. 2009 Apr;58(4):773-95. [PubMed]

2. Verspohl EJ. Novel therapeutics for type 2 diabetes: incretin hormone mimetics (glucagon-like peptide-1 receptor agonists) and dipeptidyl peptidase-4 inhibitors. Pharmacol Ther. 2009 Oct;124(1):113-38. [PubMed]

3. Deacon CF. Circulation and degradation of GIP and GLP-1. Horm Metab Res. 2004 Nov-Dec;36(1112):761-5. [PubMed]

4. Adelhorst K, Hedegaard BB, Knudsen LB, Kirk O. Structure-activity studies of glucagon-like peptide- 1 . J Biol Chem. 1994March 4;269(9):6275-8. [PubMed]

5. Eng J, Kleinman WA, Singh L, Singh G, Raufman JP. Isolation and characterization of exendin-4, an exendin-3 analogue, from Heloderma suspectum venom. Further evidence for an exendin receptor on dispersed acini from guinea pig pancreas. $J$ Biol Chem. 1992 Apr 15;267(11):7402-5. [PubMed]

6. Barnett AH. Lixisenatide: evidence for its potential use in the treatment of type 2 diabetes. Core Evid. 2011; 6:67-79. [PubMed]

7. Knudsen LB, Lau J. The Discovery and Development of Liraglutide and Semaglutide. Front Endocrinol (Lausanne). 2019 April 12;10:155. [PubMed]

8. Ahrén B. DPP-4 Inhibition and the Path to Clinical Proof. Front Endocrinol (Lausanne). 2019 June 19;10: 376. [PubMed]

9.Cai W, Jiang L, Xie Y, Liu Y, Liu W, Zhao G. Design of SGLT2 Inhibitors for the Treatment of Type 2 Diabetes: A History Driven by Biology to Chemistry. Med Chem. 2015; 11(4): 317-28. [PubMed]

10. Pearson S, Kietsiriroje N, Ajjan RA. Oral Semaglutide In The Management Of Type 2 Diabetes: A Report On The Evidence To Date. Diabetes Metab Syndr Obes. 2019 Dec 2; 12:2515-2529.[PubMed]

11. PRAC concludes that diabetes medicine canagliflozin may contribute to risk of toe amputation. EMA. February 10 2017. EMA/76661/2017. [Internet]

12. Bailey CJ, Day C. The future of new drugs for diabetes management. Diabetes Res Clin Pract. 2019 Sep;155:107785. [PubMed]

13. Davies MJ, D'Alessio DA, Fradkin J, Kernan W, Mathieu C, Mingrone $\mathrm{G}$, et al. Management of Hyperglycemia in Type 2 Diabetes, 2018. A Consensus Report by the American Diabetes Association (ADA) and the European Association for the Study of Diabetes (EASD). Diabetes Care. 2018 Dec;41(12):2669-2701. [PubMed]

14. FDA News Release. FDA approves new treatment for a type of heart failure. May 05, 2020. [Internet]

15. Marso SP, Daniels GH, BrownFrandsen K, Kristensen P, Mann JF, Nauck MA, et al. Liraglutide and car- diovascular outcomes in type 2 diabetes. N Engl J Med. 2016 July 28; 375:311-22. [PubMed]

16. Marso SP, Bain SC, Consoli A, Eliaschewitz FG, Jodar E, Leiter LA, et al. Semaglutide and cardiovascular outcomes in patients with type 2 diabetes. N Engl J Med. 2016 Nov 10;375:1834-44. [PubMed]

17. Hernandez AF, Green JB, Janmohamed S, D'Agostino RB, Granger CB, Jones NP, et al. Albiglutide and cardiovascular outcomes in patients with type 2 diabetes and cardiovascular disease (Harmony Outcomes): a double-blind, randomized placebo-controlled trial. Lancet. 2018 Oct 27;392:1519-1529. [PubMed]

18. Gerstein HC, Colhoun HM, Dagenais GR, Diaz R, Lakshmanan M, Pais $\mathrm{P}$, et al. Dulaglutide and cardiovascular outcomes in type 2 diabetes (REWIND): double-blind, randomized placebo-controlled trial. Lancet. 2019 July 13;394(10193):121-130. [PubMed]

19. Zinman B, Wanner C, Lachin JM, Fitchett D, Bluhmki E, Hantel S, et al. Empagliflozin, cardiovascular outcomes, and mortality in type 2 diabetes. N Engl J Med. 2015 Nov 26;373(22):2117-2128. [PubMed]

20. Neal B, Perkovic V, Mahaffey KW, de Zeeuw D, Fulcher G, Erondu $\mathrm{N}$, et al. Canagliflozin and Cardiovascular and Renal Events in Type 2 Diabetes. N Engl J Med. 2017 Aug 17;377(7):644-657. [PubMed]

21. Wiviott SD, Raz I, Bonaca MP, Mosenzon O, Kato ET, Cahn A, et al. 
Dapagliflozin and cardiovascular outcomes in type 2 diabetes. $N$ Engl J Med. 2019 Jan 24;380(4):347-357. [PubMed]

22. Tankova T, Borisova AM, Orbetzova M.[Recommendations for Good Clinical Practice in Diabetes Mellitus.] [in Bulgarian] Bulgarian Society of Endocrinology. 2019. p.96. [nternet]
23. Buse JB, Wexler DJ, Tsapas A, Rossing P, Mingrone G, Mathieu C, et al. 2019 Update to: Management of Hyperglycemia in Type 2 Diabetes, 2018. A Consensus Report by the American Diabetes Association (ADA) and the European Association for the Study of Diabetes (EASD). Diabetes Care. 2020 Feb;43(2):487-493. [PubMed]

Please cite this article as: Tsvetkova A, Mihaylova S. New approaches in the treatment of Type 2 diabetes - transition from glucose-centred to patient-centred model. J of IMAB. 2021 Jul-Sep;27(3):3885-3892.

DOI: https://doi.org/10.5272/jimab.2021273.3885

Received: 02/02/2021; Published online: 18/08/2021

\section{Address for correspondence:}

Antoaneta Tsvetkova

Medical College, Medical University - Varna,

84, Tsar Osvoboditel str., Varna, Bulgaria

E-mail: antoaneta.tsvetkova11@gmail.com, 